Review

\title{
Recent Advances in Ocean Nuclear Power Plants
}

\section{Kang-Heon Lee ${ }^{1}$, Min-Gil Kim ${ }^{2}$, Jeong Ik Lee ${ }^{2}$ and Phill-Seung Lee 1,*}

1 Department of Mechanical Engineering, Korea Advanced Institute of Science and Technology, 291 Daehak-ro, Yuseong-gu, Daejeon 34141, Korea; E-Mail: welcome@kaist.ac.kr

2 Department of Nuclear and Quantum Engineering, Korea Advanced Institute of Science and Technology, 291 Daehak-ro, Yuseong-gu, Daejeon 34141, Korea; E-Mails: gggggtt@kaist.ac.kr (M.-G.K.); jeongiklee@kaist.ac.kr (J.I.L.)

* Author to whom correspondence should be addressed; E-Mail: phillseung@kaist.edu; Tel.: +82-42-350-1512.

Academic Editor: Hiroshi Sekimoto

Received: 30 August 2015 / Accepted: 1 October 2015 / Published: 14 October 2015

\begin{abstract}
In this paper, recent advances in Ocean Nuclear Power Plants (ONPPs) are reviewed, including their general arrangement, design parameters, and safety features. The development of ONPP concepts have continued due to initiatives taking place in France, Russia, South Korea, and the United States. Russia's first floating nuclear power stations utilizing the PWR technology (KLT-40S) and the spar-type offshore floating nuclear power plant designed by a research group in United States are considered herein. The APR1400 and SMART mounted Gravity Based Structure (GBS)-type ONPPs proposed by a research group in South Korea are also considered. In addition, a submerged-type ONPP designed by DCNS of France is taken into account. Last, issues and challenges related to ONPPs are discussed and summarized.
\end{abstract}

Keywords: ocean nuclear power plants; floating; gravity based structure (GBS); submerged; safety features; ocean environments; small modular reactor (SMR)

\section{Introduction}

The occurrence of the Fukushima Daiichi nuclear disaster again alerted society to the risks of nuclear power plants (NPPs) [1]. Even though NPPs have potentially devastating consequences, they cannot be completely removed from the current energy portfolio because nuclear power has the smallest 
full-lifecycle carbon footprint among all energy sources and is one of the cheapest available energy sources [2]. In addition, there are still large areas with low human populations around the whole world where the problems of sea water desalination and provision of electricity must be solved. Therefore, it is better to enhance the safety features of NPPs in order to use nuclear power continuously and safely, than to stop using it.

One possible solution for using nuclear power safely could involve moving the conventional nuclear power plants from land to ocean in an effort to enhance safety. In general, this type of nuclear power plant is called an Ocean Nuclear Power Plant (ONPP) and it may also be attractive with regard to future expansion. This could be achieved by allocation of space during the first stage of development or by adding other structures or facilities installed adjacent to existing facilities, without concern for acquiring new land or receiving negative public feedback [3]. Recently, several countries have been pioneering the development and application of ONPPs utilizing the innovative features of Small Modular Reactors (SMRs) [4-7], as well as medium to large size reactors.

As many nuclear engineers already know, nuclear engineering for power generation actually began with attempts to utilize nuclear energy in ocean environments. However, until the early $2000 \mathrm{~s}$ the actual application of nuclear energy in the oceans was limited to military applications with only a few exceptions (e.g., NS Savannah, Otto Hahn, Mutsu and Russian icebreakers) [8].

The Russian project to develop floating nuclear power stations started in the early 2000s [9,10]. The Akademik Lomonosov, Russia's first ONPP driven by KLT-40s [11,12], was launched on June 2010. It will be deployed at Vilyuchinsk, in the Kamchatka region in Russia in 2016. More recently, a team led by Jacopo Buongiorno at the Massachusetts Institute of Technology (MIT), in collaboration with researchers from the University of Wisconsin and the Chicago Bridge and Iron Company, is developing a new concept $[13,14]$ for an Offshore Floating Nuclear Plant (OFNP) on a spar-type floating platform.

In 2011, a submerged type ONPP, named Flexblue [15-17] was proposed by DCNS (a state-owned defense group) from France. It was designed to reside on the sea bottom 60-100 m deep, up to $15 \mathrm{~km}$ offshore. Preliminary studies showed that it is possible for Flexblue to produce anywhere from 50 to $250 \mathrm{MW}$ of nuclear energy and researchers emphasize that the reactor is thought to be resistant to natural disasters such as earthquakes, tsunami, and flooding. When first announced, it was said that DCNS intended to start building a prototype Flexblue unit in 2013 in its shipyard at Cherbourg, for launch and deployment in 2016.

The Gravity Based Structure (GBS) [18] type ONPPs developed by the Korea Advanced Institute of Science and Technology (KAIST) [19,20] in South Korea are also considered. This concept makes use of an existing nuclear reactor, named the System-integrated Modular Advanced ReacTor (SMART) [21,22] and the Advanced Power Reactor 1400 (APR1400) [23] developed by the Korea Hydro \& Nuclear Power (KHNP) Co., Ltd. (Seoul, South Korea) While modification of the general arrangement, safety features, and principal design parameters are minimal, and safety features against tsunami and earthquakes are being enhanced. This design makes use of the so-called modularization method [24] to properly separate the NPP facilities into multiple GBS modules.

This paper presents a survey of recent advances in the ONPPs of France, Russia, South Korea, and the United States. In the following section, we categorize various types of ONPPs as floating, GBS, and submerged types, and review their general arrangement, dimensions, design parameters, and safety features. 


\section{Floating-Type ONPPs}

\subsection{Akademik Lomonosov (Russia)}

In Russia, there are spacious areas with low human populations, ports along the North Sea Route and the Far East Coast, as well as isolated fields of mineral deposits and military bases. Provision of sea water desalination and electricity are becoming more and more demanding tasks, not only in Russia and but in many other places around the world.

For these reasons, Floating Power Units (FPUs) with KLT-40S, Atomny Blochny Vodyanoy (ABV)-6M, Vodyanoi Blochnyi Energetichesky Reactor (VBER)/OKBM, RIT, and NIKA-70 reactors have been considered for the provision of electric and thermal energy, and of seawater desalination. Because the KLT-40S [12] reactor plant designs are the best developed and most appropriate arrangement of NPP for land or use on a non-self-propelled watercraft, it was chosen for mounting on Russia's first floating-type NPP, named Akademik Lomonosov [25-27], as shown in Figure 1. This SMR-mounted floating-type FPU was launched on 30 June 2010 and its reactors are expected to be delivered in 2016.

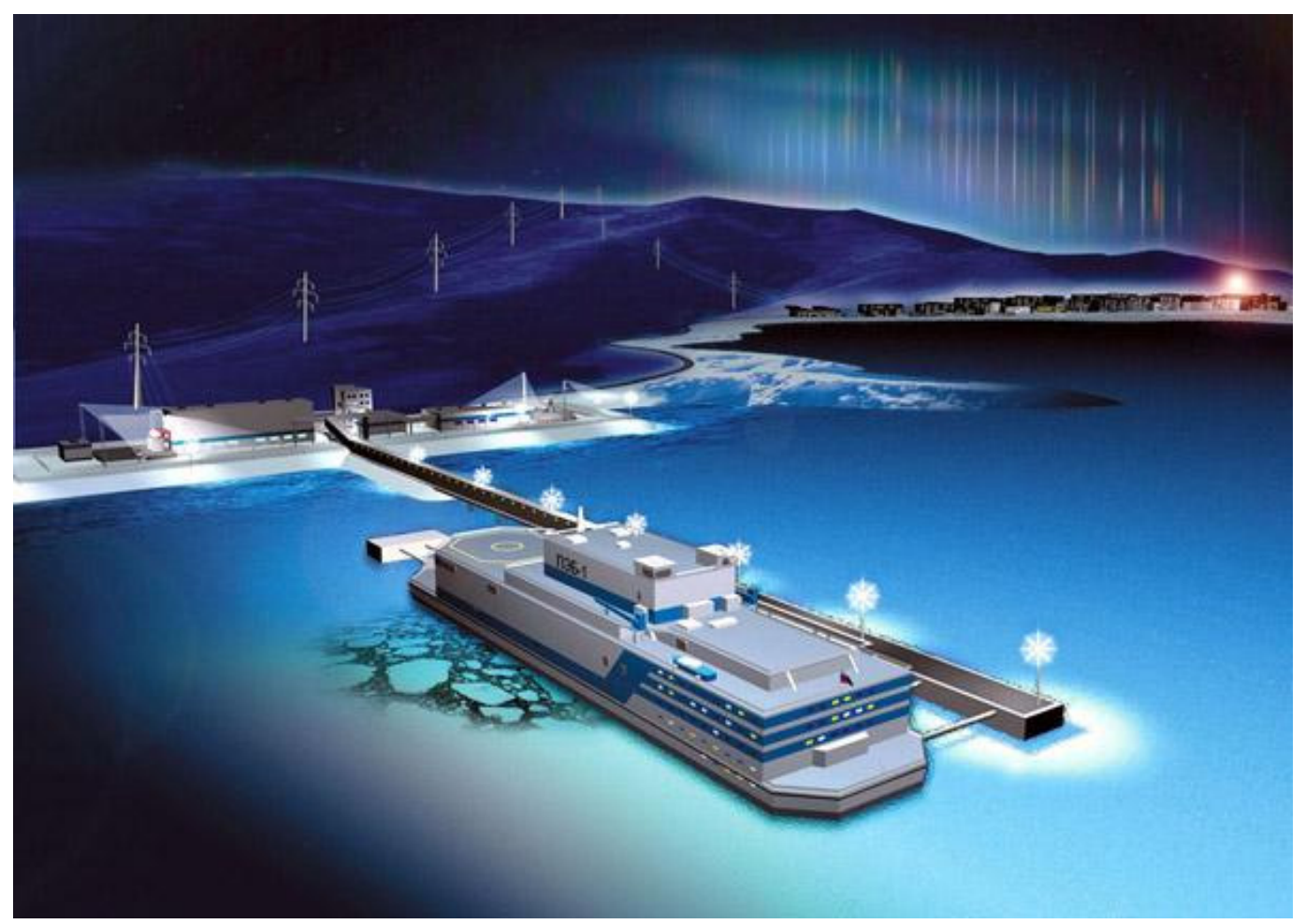

Figure 1. Akademik Lomonosov, Afrikantov OKBM [12].

Akademik Lomonosov has a length of $144 \mathrm{~m}$ and width of $30 \mathrm{~m}$. It has a displacement of 21,500 ton and a crew of 70 people. For power generation, it has two KLT-40S reactors providing up to $70 \mathrm{MWe}$ with $300 \mathrm{MWt}$. The status of this reactor is that the first unit is under construction. The key parameters [7] are summarized in Table 1 and Figure 2 shows a drawing of the KLT-40S. The emergency cool-down system (ECS) for the KLT-40S reactor was also developed [28] to remove the residual heat released when the power station is in blackout. The safety concept developed by Afrikantov OKBM received international recognition, including a level of review by the IAEA (IAEA safety guidelines \# 50-SG-D11). 
Table 1. Key parameters of KLT-40S [7].

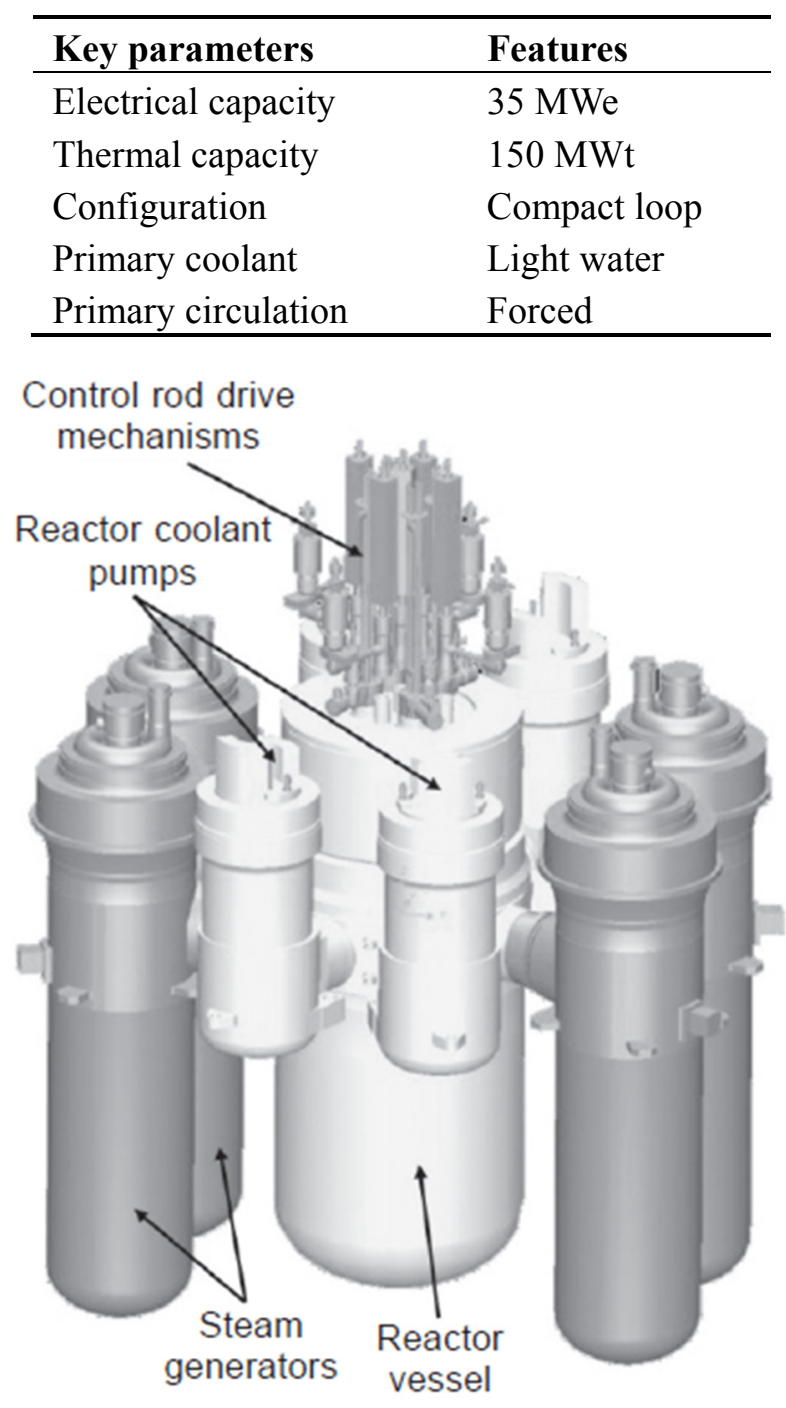

Figure 2. KLT-40S, Afrikantov OKBM [11].

The Akademik Lomonosov could also be converted into a desalination plant [29] producing 240,000 $\mathrm{m}^{3}$ of fresh water per day, an immensely interesting solution for seaside countries with scarce water resources located in Northern Africa and the Middle East. The Akademik Lomonosov, with a lifespan of 40 years and a 4 years construction period for the Nth-of-a-kind plant, will be re-fueled every three years and will have a 12 years service cycle, when the plant will be moved to undergo service and maintenance at a Baltic shipyard. The key design principles of the plant are summarized below:

- A FPU is assembled completely at a shipyard with the use of a well-developed technology for constructing atomic icebreakers and navy ships in Russia.

- After completing comprehensive tests and a customer acceptance procedure, an FPU is tugged to its mooring site where it is connected to a coastal power network to start operation.

- The plant needs onsite auxiliary facilities and lines for transmitting electricity and heat to the shore.

- The plant is mobile and can be stationed anywhere onshore and even on the beds of big rivers. 
In addition, the safety regulations of the Akademik Lomonosov make provisions against external hazards including:

- Unsinkability of the floating unit is assured due to partition of the casing into waterproof compartments and sealing is activated after flooding of two adjacent compartments. When any two adjacent compartments of any board are flooded, maximum hydrostatic tilt is no more than $3^{\circ}$.

- Protection of the reactor in a collision of the floating unit with another ship is assured due to placement of the reactor in the central part of the casing under the double deck.

- The upper deck of the station has a multi-layer structure that makes it possible to damp the kinetic energy of falling air craft due to the usage of special construction units that distribute the force of an impact over a large area.

- The floating unit operates normally during storm wind with speeds up to $80 \mathrm{~m} / \mathrm{s}$.

- Seismic stability and protection from storm waves and tsunami, are assured due to use of natural or artificial barriers (islands, forelands, and wave breakers), or by placing the floating unit a safe distance from the shore.

The floating design allows a decrease in the scope and cost of capital construction in the area where the NPP will be located. When NPPs are exported, the matters of nuclear waste storage, NPP maintenance, and decommissioning on completion of service life, are handled by the plant operator at nuclear maintenance facilities available in Russia.

\subsection{Offshore Floating Nuclear Plant (USA)}

Recently, as shown in Figure 3, a research group at MIT in the United States proposed an OFNP [13,14] based on a spar-type floating platform with catenary mooring [30]. The OFNP employing the spar platform has the following characteristics:

- The OFNP could have a low center of gravity for hydrodynamic and static stability, and could eliminate the transmission of seismic loads from the ocean floor, as well as loads from Tsunami, waves, and wind.

- The hydrodynamic and static stability can be tuned using an added steel skirt, seen in Figure 4.

- The spar offers the better protection to the reactor itself when compared to other offshore platform design, such as semi-submersibles or floating barges.

- The spar-type OFNP design can be constructed without all structural concrete, except radiation shielding around the spent fuel pool. Using less concrete helps to reduce cost and construction time.

- The spar enables the reactor and containment to be located at a level below the waterline, which enhances physical protection from plane crashes and collisions with ships.

- This design provides access to the ultimate heat sink: the ocean. 


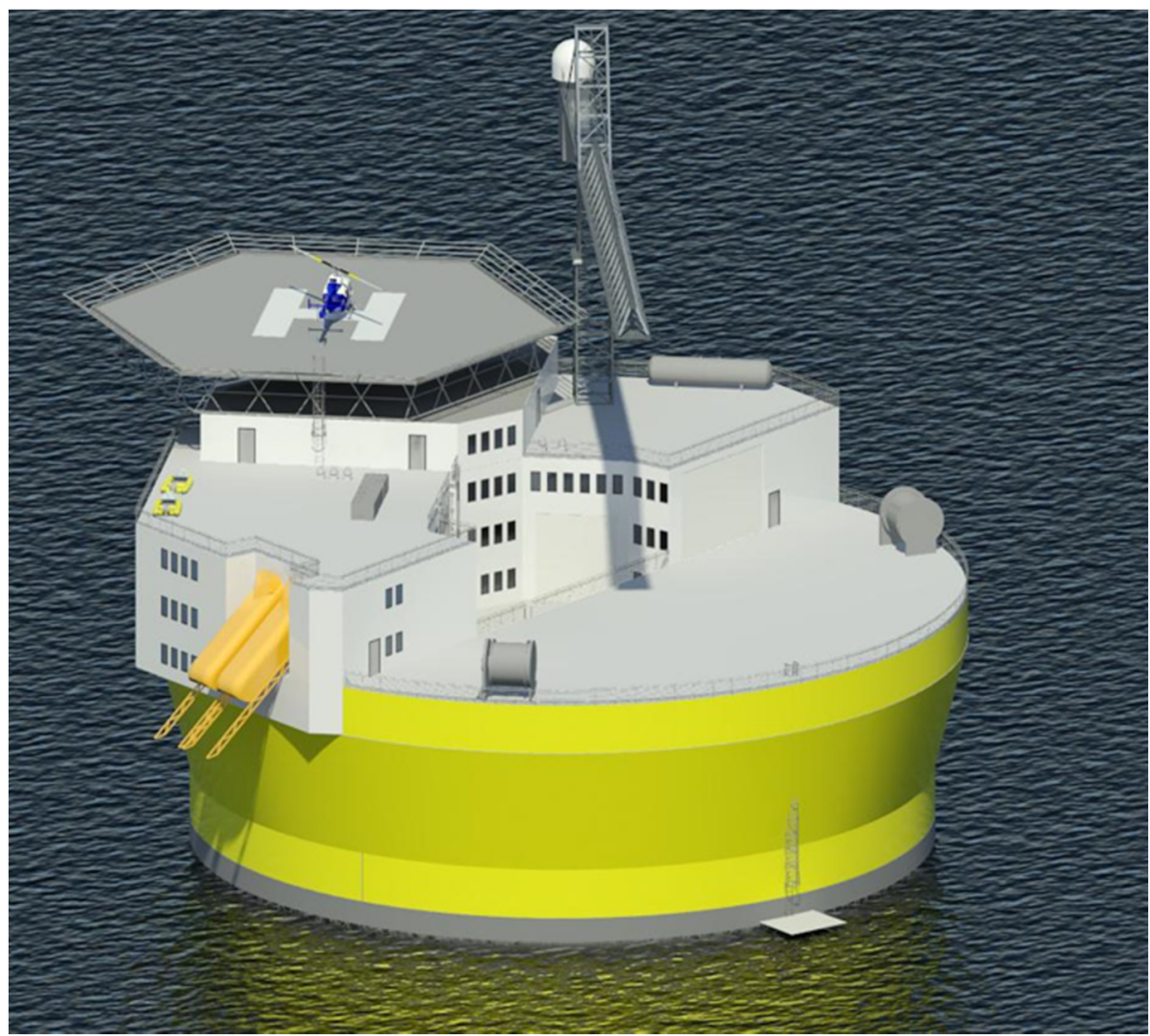

Figure 3. 3-D rendering of OFNP [13].

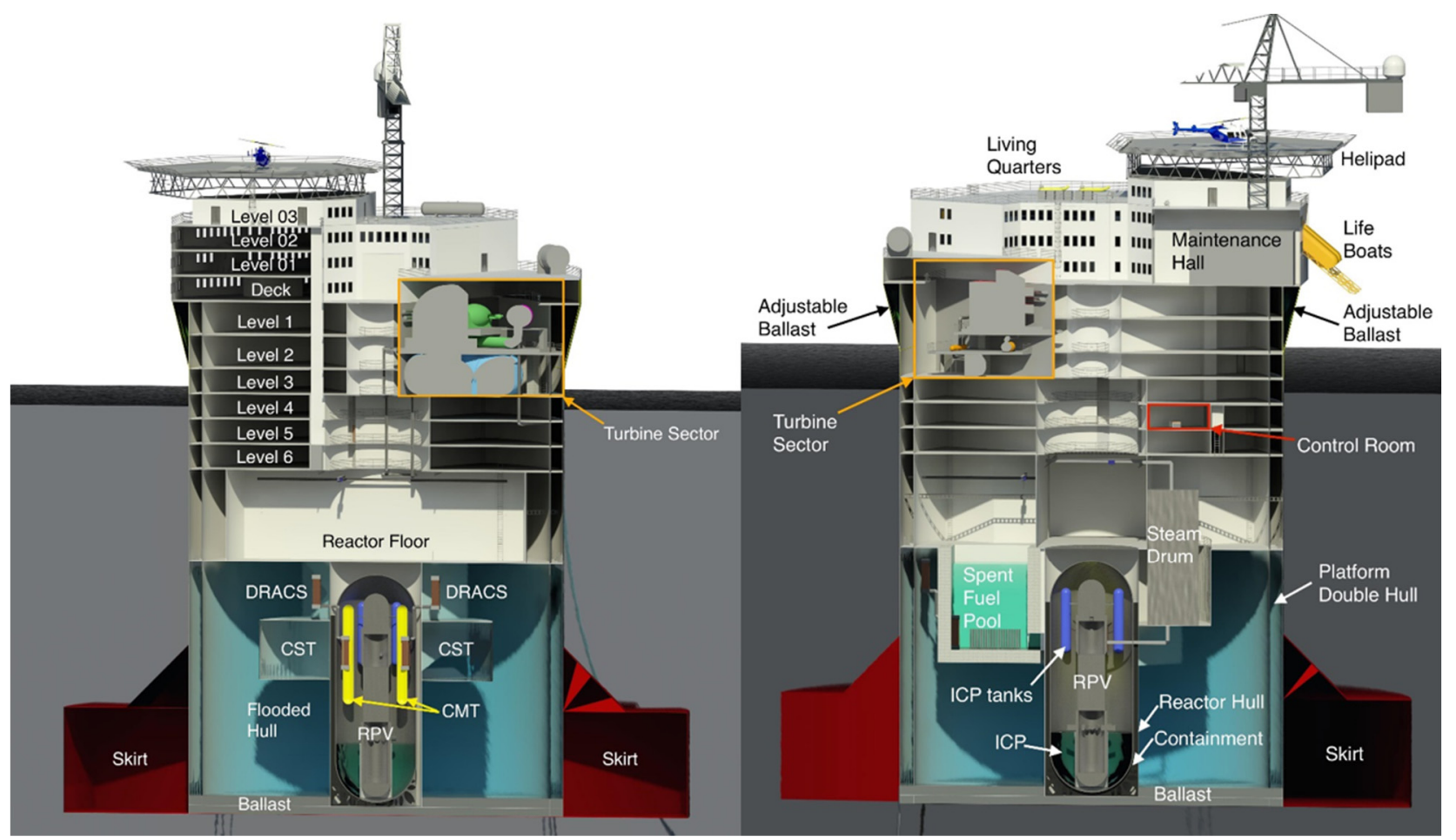

Figure 4. 3-D cutaway view of OFNP [14].

The target power of the OFNP is from 300 to 1100 MWe. This OFNP is built in a shipyard and transported to its mooring site. When its service lifetime is over, the OFNP is transported to a shipyard where decommissioning can be performed. Therefore, the environmental integrity of the mooring site is 
expected to be maintained. The plant is to be located 10 to $20 \mathrm{~km}$ offshore in $100 \mathrm{~m}$ of water depth. Because this water depth is not typically found near a coast, threats from earthquakes and Tsunami are eliminated, as mentioned above.

The size of the spar design, including the OFNP (300 MWe), is about $45 \mathrm{~m}$ in diameter (without skirt at the base); the skirt diameter is $75 \mathrm{~m}$ ). The OFNP design is $74 \mathrm{~m}$ tall from the bottom of the hull to top, has an operational draft of $48.5 \mathrm{~m}$, and a total weight of about 38,200 ton when the skirt is empty [13]. The main deck is approximately $12.5 \mathrm{~m}$ above the water and the catenary mooring system will allow the platform to move up and down in large amplitude waves, but restrain most lateral translation.

For stable operation, the elevation of the metacenter should be above the elevation of the center of gravity. By locating the heavy nuclear components low in the structure, hydrostatic stability is obtained in a spar-type OFNP. The metacenter is $8 \mathrm{~m}$ above the center of gravity in the current design, so that hydrostatic stability can be guaranteed. Modeling of this design indicates that the natural heave frequency is sufficiently far from the range of peak storm-wave frequencies. The preliminary design goals and corresponding design features of this OFNP are well organized in Table 2.

Table 2. Design goals and the parameters of the OFNP [14].

\begin{tabular}{ll}
\hline Design goals & Design parameters \\
\hline Platform floatation & Spar diameter, spar hull layout \\
\hline Platform hydrostatic stability & $\begin{array}{l}\text { Spar draft and diameter, heavy component layout, ballast, } \\
\text { spar skirt dimensions }\end{array}$ \\
\hline Adjustable draft & Skirt dimensions and ballasting system \\
\hline $\begin{array}{l}\text { Protection of critical nuclear systems from } \\
\text { extreme natural events and terrorist attacks }\end{array}$ & $\begin{array}{l}\text { Nuclear island layout, location of control room, battery } \\
\text { room and spent fuel pool, deck elevation, bulkhead layout }\end{array}$ \\
\hline Ease of access to ocean heat sink & Nuclear island layout, reactor hull design \\
\hline Ease of refueling & Location of spent fuel pool and condensate storage tank \\
\hline $\begin{array}{l}\text { Freshwater production for crew and steam } \\
\text { cycle makeup needs }\end{array}$ & Size and location of desalination units \\
\hline Crew comfort and safety & $\begin{array}{l}\text { Living quarter layout, radiological controlled area layout, } \\
\text { location and number of lifeboats }\end{array}$ \\
\hline Ease of construction & $\begin{array}{l}\text { Spar dimensions and layout, materials chosen, } \\
\text { overall platform geometry }\end{array}$ \\
\hline Plant resilience to water damage and flooding & $\begin{array}{l}\text { Critical electronics locations, water-tight compartment } \\
\text { layout, condensate storage tanks location }\end{array}$ \\
\hline
\end{tabular}

Figure 4 shows a 3-D cutaway view of the MIT OFNP design [14]. The nuclear reactor and containment is located below sea level. It has a single desalination plant to provide fresh water to the crew and plant. Desalinated water is stored in Condensate Storage Tank (CST) and is not used for emergency cooling. The reactor, its containment, and safety systems are located below the reactor floor. The condenser takes in water through a neutrally buoyant trunk that extends below the hull of the platform, where the water is naturally a few degrees cooler, and it exhausts water just below sea level.

The OFNP has a large chamber that can be flooded with seawater at the bottom of the spar. The flood chamber stores Direct Reactor Auxiliary Cooling System (DRACS) units, which remove decay heat passively and indefinitely in accident situations, when cooling through the steam generators cannot be 
provided [14]. Figure 5 shows a 2-D lateral view of the locations of the DRACS and CST. The Emergency Core Cooling System (ECCS) and ocean-based Passive Containment Cooling System (PCCS) keep the fuel covered and the containment pressure low during LOCAs (Figure 6).

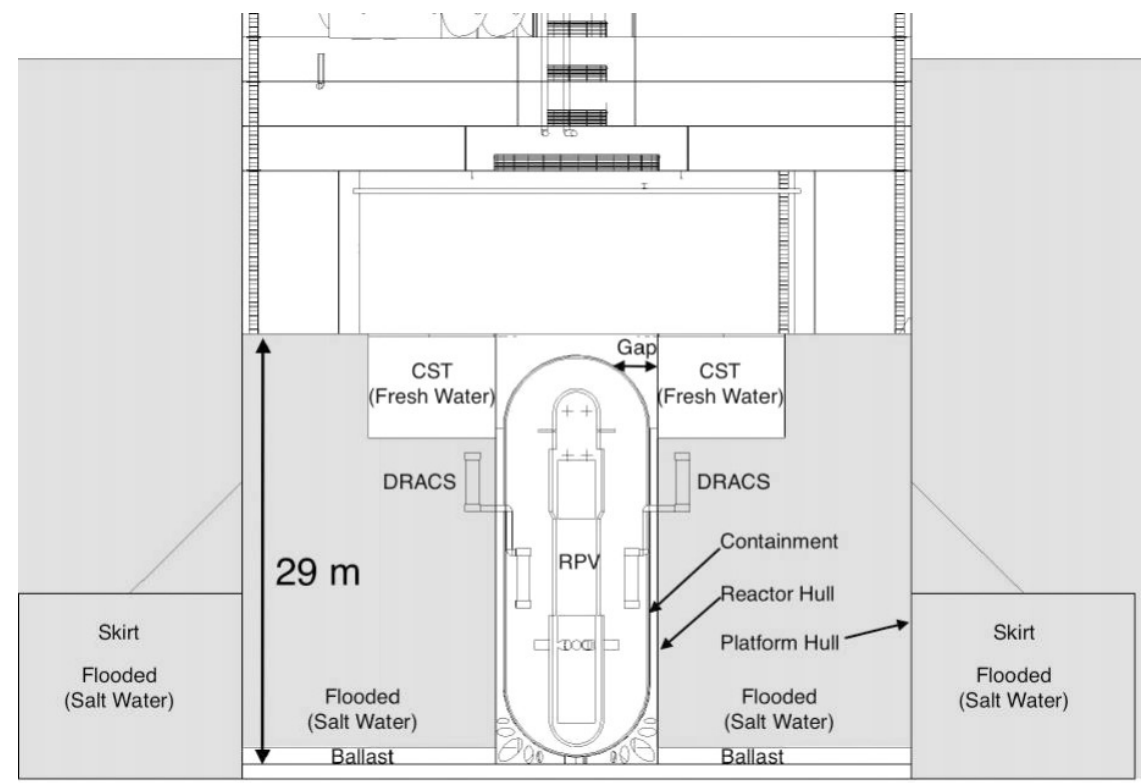

Figure 5. 2-D lateral view showing the location of DRACS and CST [13,14].

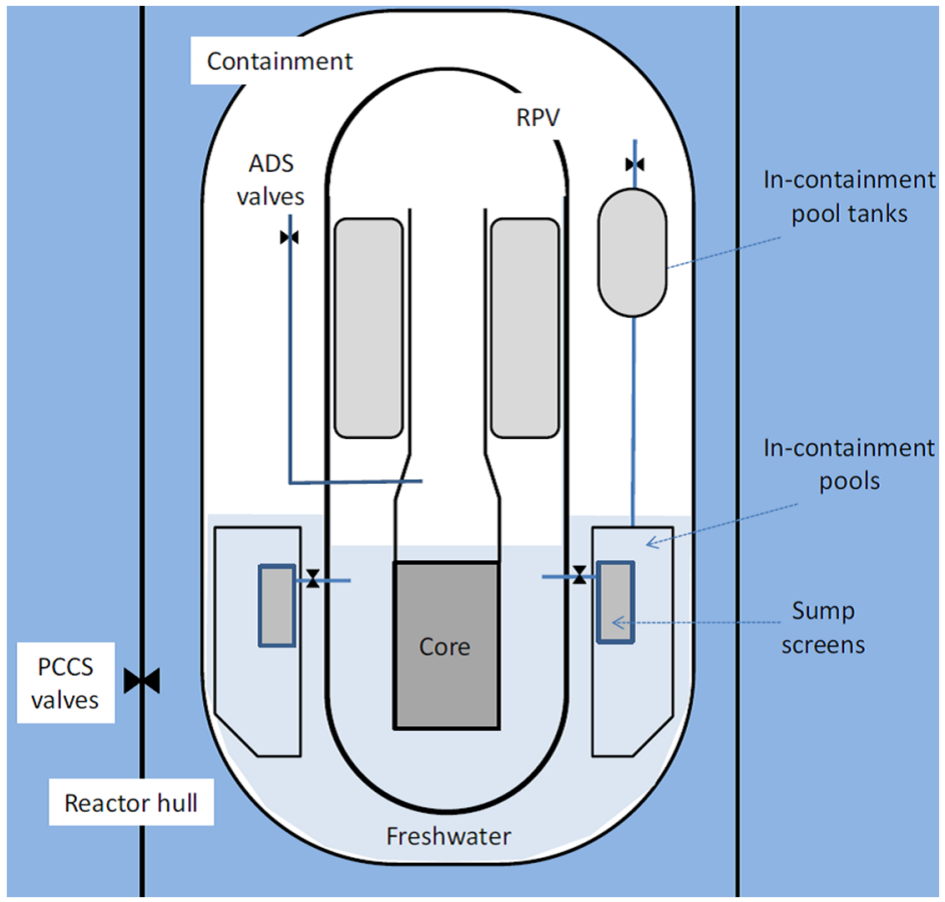

Figure 6. Schematic of core and containment cooling in post-LOCA situation [14].

For severe accidents with core melting, the In-Vessel Retention (IVR) approach is adopted and the PCCS again ensures indefinite and passive heat removal through the containment shell (Figure 7); see Reference [14] for detailed explanations. 


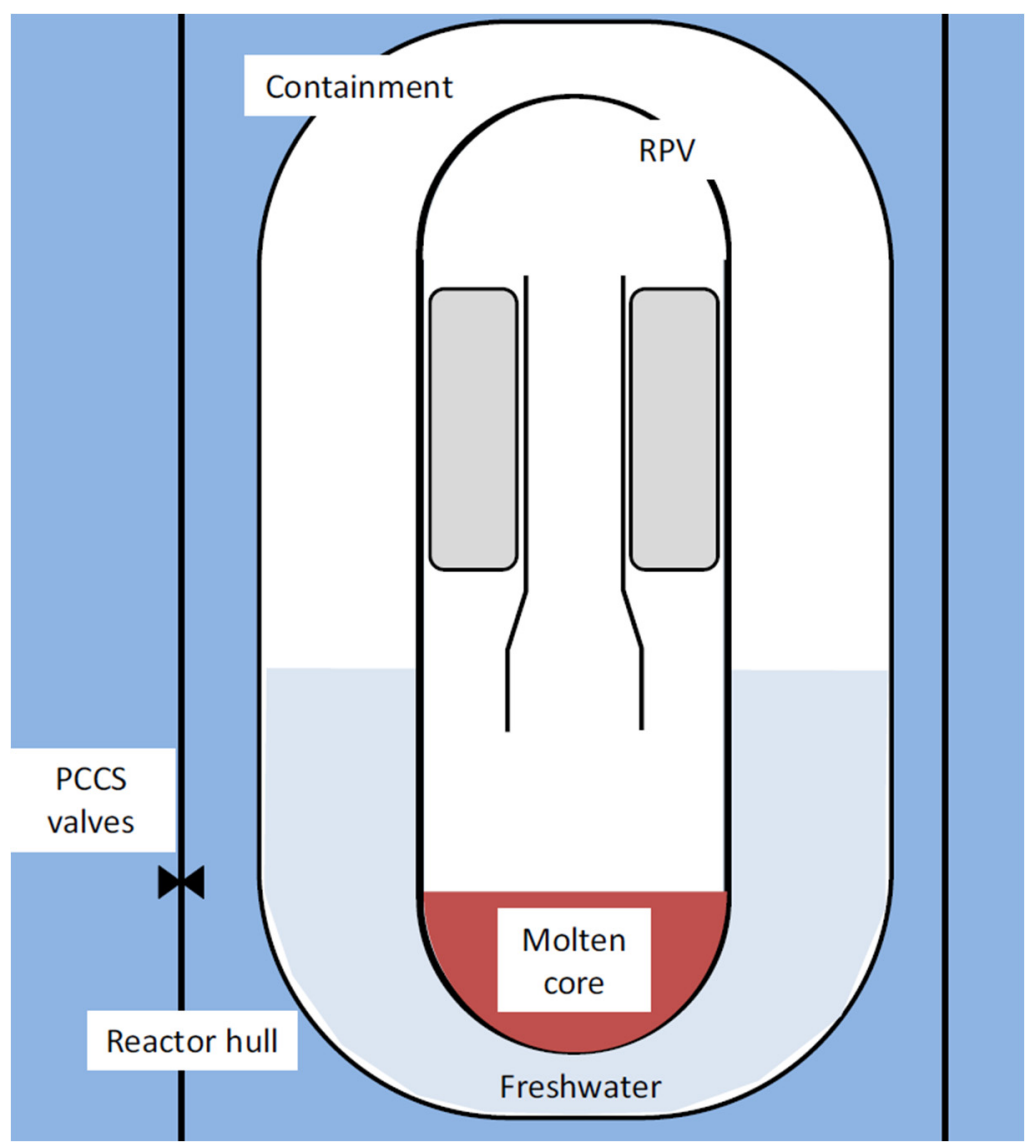

Figure 7. Schematic of in-vessel retention of corium [14].

\section{GBS Type ONPP}

Developments led by the research group in South Korea suggested the idea of adapting a GBS for an ONPP. The key concept of the GBS-type ONPP centers on its use of a GBS as a container and a support structure in addition to the use of a modular design (as employed in ship fabrication) at an on-site factory facility. When the fabrication and assembly of the GBS and NPP components are completed, the GBS modules are launched and towed by tugboats to the ONPP mooring site. There, the modules are placed on the seabed using a ballasting system. Finally, the GBS modules are rigidly connected using steel bars, post-tensioning steel cables, and cement paste [18]. At this point, the GBS modules act as a single rigid structure, thus mitigating risks related to pipelines and cables. The details are shown in Figure 8. The four basic steps of this procedure are explained below:

- Step 1: A GBS is constructed in a dry dock, the fabricated components of the NPP are assembled, and the installation site is prepared at the same time.

- Step 2: NPP modules (assemblages of NPP components) are mounted on the GBS. In this step, the first inspections and testing of the modularized facilities are required prior to launching.

- Step 3: The GBS-based ONPP is floated and towed to the installation site by tugboats. At the installation site, the structure is settled on the seabed using a ballasting system.

- Step 4: Nuclear fuel loading and system testing procedures are implemented after construction of the top-side facilities. Finally, the GBS-type ONPP is ready to supply electricity to land after all tests are complete. 


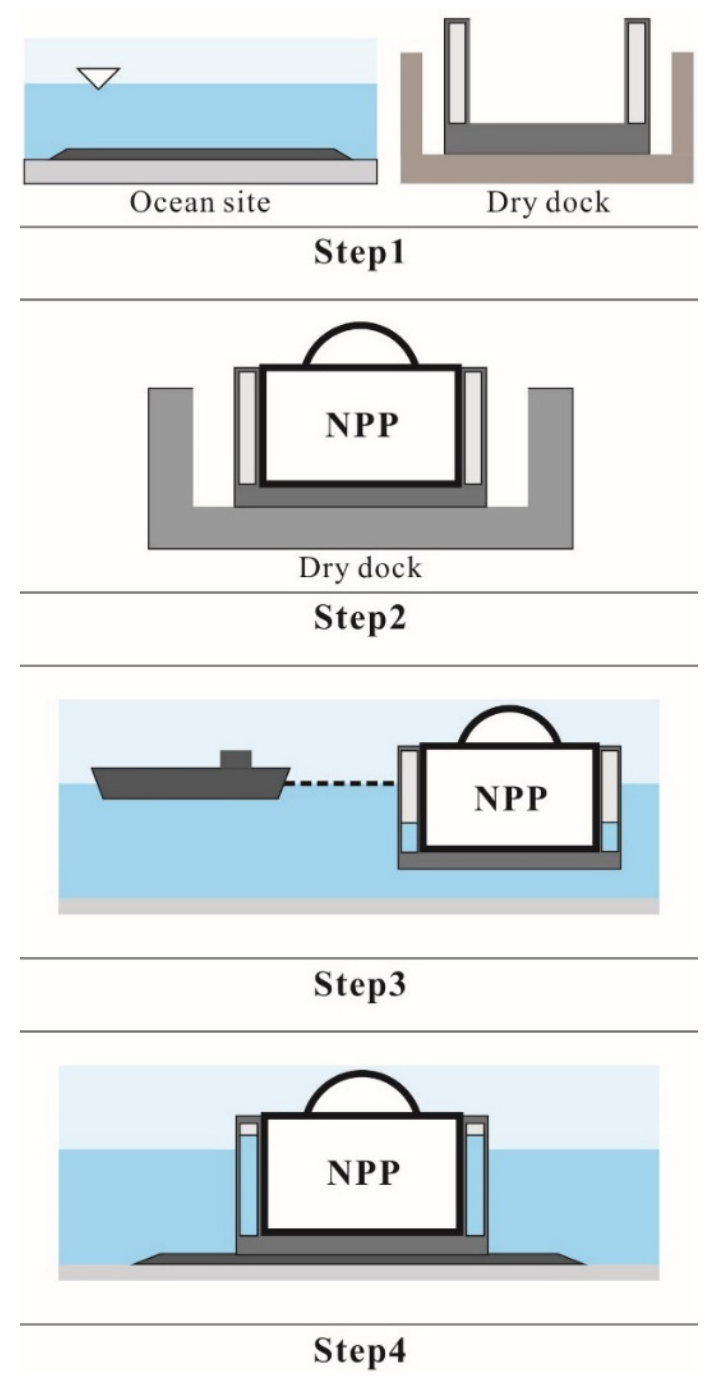

Figure 8. Key concept of the GBS-type ONPP [19].

Considering the design requirements and parameters in Table 3, the GBS-type ONPP was developed from existing NPP models in South Korea.

Table 3. Design requirements and parameters of GBS type ONPPs [19].

\begin{tabular}{lll}
\hline & Requirements & Parameters \\
\hline & Radiation protection & Nuclear/non-nuclear area \\
& Safety requirements (Internal) & Core damage frequency, Containment failure frequency, \\
Common with NPPs & Occupation radiation exposure, Turbine missile strike area \\
& Safety requirements (External) & Seismic, Tsunami, Storm, Aircraft collision \\
& Construction period and simplicity & Modularization of facilities \\
\hline
\end{tabular}


Table 3. Cont.

\begin{tabular}{|c|c|c|}
\hline & Requirements & Parameters \\
\hline \multirow{7}{*}{ Special for ONPP } & Movable and transportable in offshore & GBS hull design, Draft limitations, Ballasting system \\
\hline & Accessibility and refueling in offshore & Ocean transportation (Ship, Helicopter, Boat) \\
\hline & Settle on the sea floor & $\begin{array}{l}\text { Seabed condition, Balanced weight distribution, } \\
\text { Seabed foundation design }\end{array}$ \\
\hline & Compact total general arrangement & $\begin{array}{l}\text { Volume and area of the NPP buildings and facilities, } \\
\text { Physical and functional connection between buildings }\end{array}$ \\
\hline & Operation condition in offshore & $\begin{array}{l}\text { Existing offshore facilities, Water depth, Current drift, } \\
\text { Weather condition }\end{array}$ \\
\hline & Safety requirements (External) & $\begin{array}{l}\text { Flooding, Ship collision, Corrosion, Run up wave } \\
\text { (Green water) }\end{array}$ \\
\hline & External hazards protection & $\begin{array}{l}\text { Reinforced concrete building, Double hull, } \\
\text { Early warning system }\end{array}$ \\
\hline
\end{tabular}

Initially, as shown in Figure 9, a large-scale ONPP model was developed [19] using the APR1400 developed by the KHNP consortium. This NPP design is the latest design that has been certified by the Korean nuclear regulatory body, and is also under construction at multiple sites around the world.

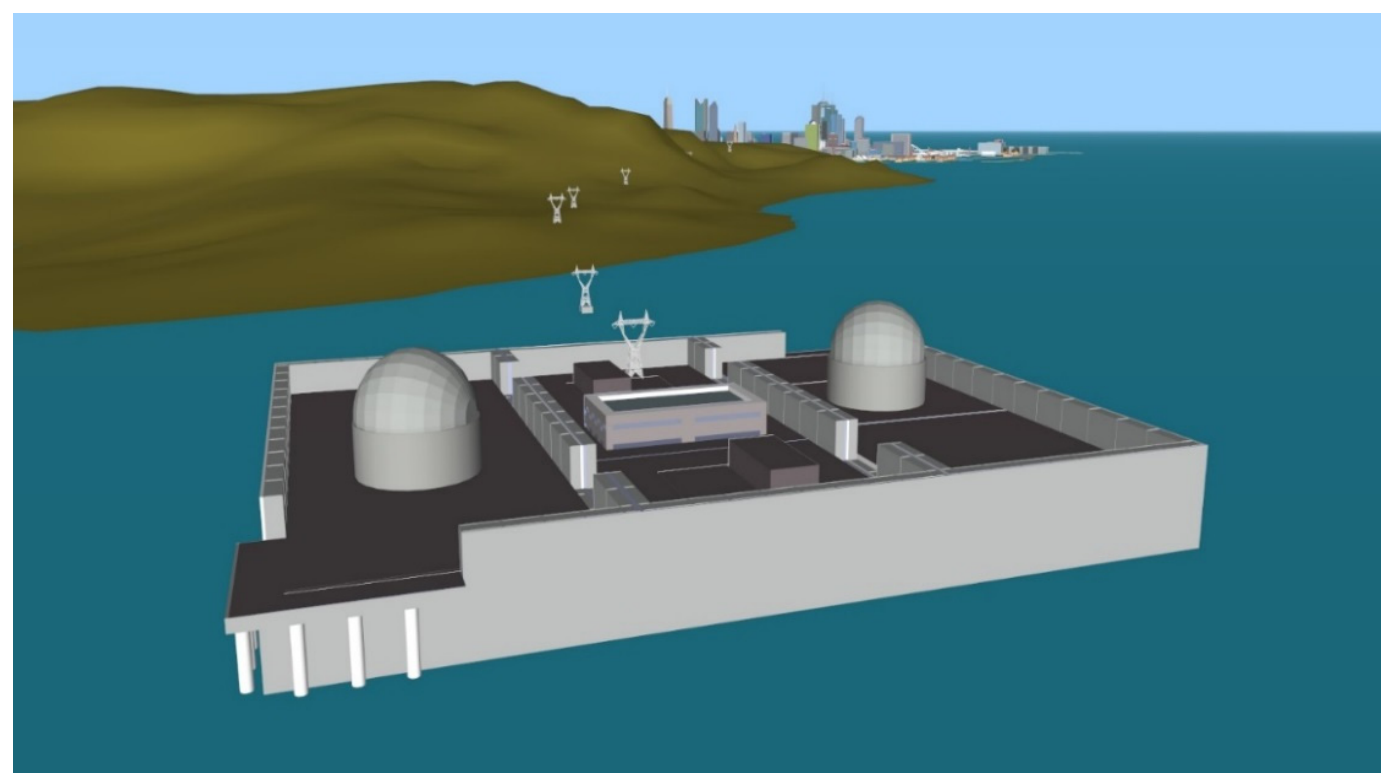

Figure 9. Large-scale ONPP (Length is $270 \mathrm{~m}$, width is $330 \mathrm{~m}$, and height is $53 \mathrm{~m}$ ) [19].

More recently, as shown in Figure 10 and Table 4, the ONPP concept was extended to SMRs [20] by adopting the SMART [21], which was developed and licensed by a Korean research and industrial consortium. SMART is a small modular reactor recently developed in South Korea. It has a capacity of $330 \mathrm{MWt}$ and 90-100 MWe power output with 40,000 ton per day of desalination capability.

A new total general arrangement for each ONPP and its basic design parameters and requirements were developed while minimizing modifications of the original APR 1400 and SMART features, such as its physical connectivity; safety systems; building arrangement; and the area, volume and weight of its buildings, to simplify the overall design process. Details, including several important design requirements and parameters of GBS type ONPPs, were presented in references [19,20]. 


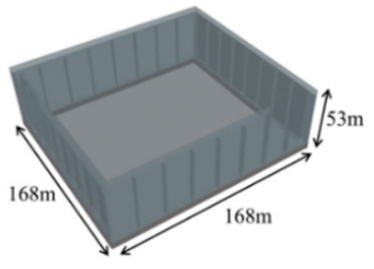

(a) Single GBS

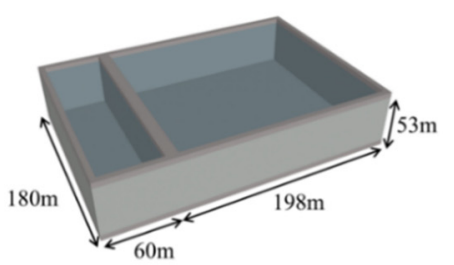

(b ) Double GBSs

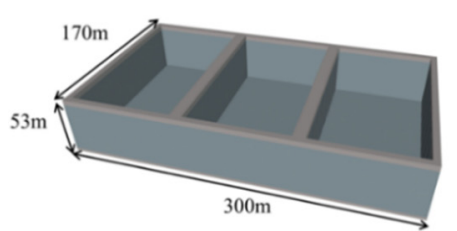

(c) Triple GBSs

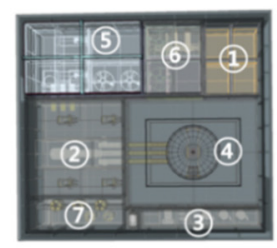

(a) Single GBS

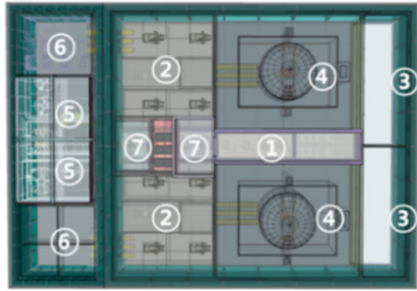

(b) Double GBSs

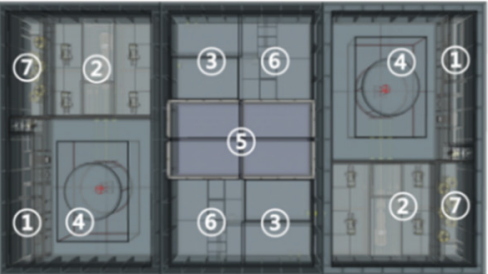

(c) Triple GBSs

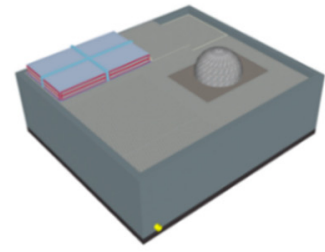

(a) Single GBS

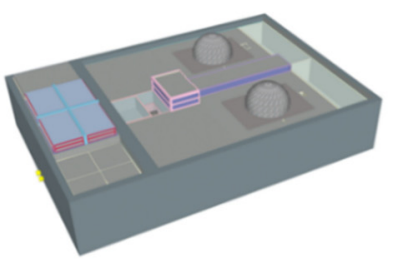

(b) Double GBSs

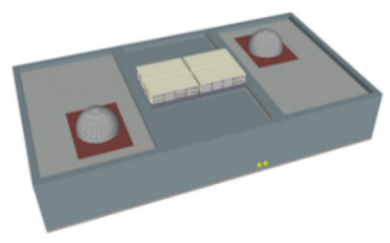

(c) Triple GBSs

Figure 10. Three types of SMART mounted on GBSs [20].

Table 4. Modularized group of SMART mounted on GBSs [14].

\begin{tabular}{|c|c|c|c|}
\hline Group & Facilities and buildings & Group & Facilities and buildings \\
\hline \multirow{3}{*}{1} & AAC D/G building & \multirow{10}{*}{5} & \multirow[b]{3}{*}{ Operator's office } \\
\hline & Aux. Boiler/oil storage building & & \\
\hline & Fresh water storage tank & & \\
\hline \multirow{7}{*}{2} & Turbine generator building & & Guard house \\
\hline & Main transformer & & Accommodation \\
\hline & Unit Aux. Transformer & & Main control building \\
\hline & Standby Aux. Transformer & & Refuge \\
\hline & Excitation transformer & & Fire pump \& water \\
\hline & Spare unit Aux. Transformer & & Wastewater treatment building and facilities \\
\hline & Other Spare transformers & & \\
\hline \multirow{6}{*}{3} & Reactor make-up water tank & \multirow{6}{*}{6} & \\
\hline & Hold-up tank & & ESW/CW Intake structure \\
\hline & Boric acid storage tank & & Chlorination building \\
\hline & EDG building & & CCW HX building \\
\hline & $\mathrm{CO}_{2}$ Storage tank & & Discharge pond and facilities \\
\hline & Other storage tanks & & \\
\hline \multirow{3}{*}{4} & Reactor building & \multirow{3}{*}{7} & \multirow{3}{*}{$\mathrm{N}_{2} \& \mathrm{H}_{2}$ storage cylinder area } \\
\hline & Aux. building & & \\
\hline & Compound building & & \\
\hline
\end{tabular}


As shown in Figure 11, the Emergency Passive Containment Cooling System (EPCCS) and the Emergency Passive Reactor-Vessel Cooling System (EPRVCS) were suggested in Reference [19] to enhance the intact safety of a GBS-type ONPP. The purpose of the EPCCS is to cool and decrease the inner pressure of the containment to prevent structural failure of the entire containment system. However, the EPCCS can sufficiently cool the containment but cannot prevent a reactor vessel failure if an accident exceeds the beyond design basis accident limit when the core is severely damaged, as in the Three Mile Island and Fukushima incidents. In order to protect the reactor vessel from failing during a severe accident, an EPRVCS was proposed; this system directly cools the reactor vessel using ballast water/seawater.

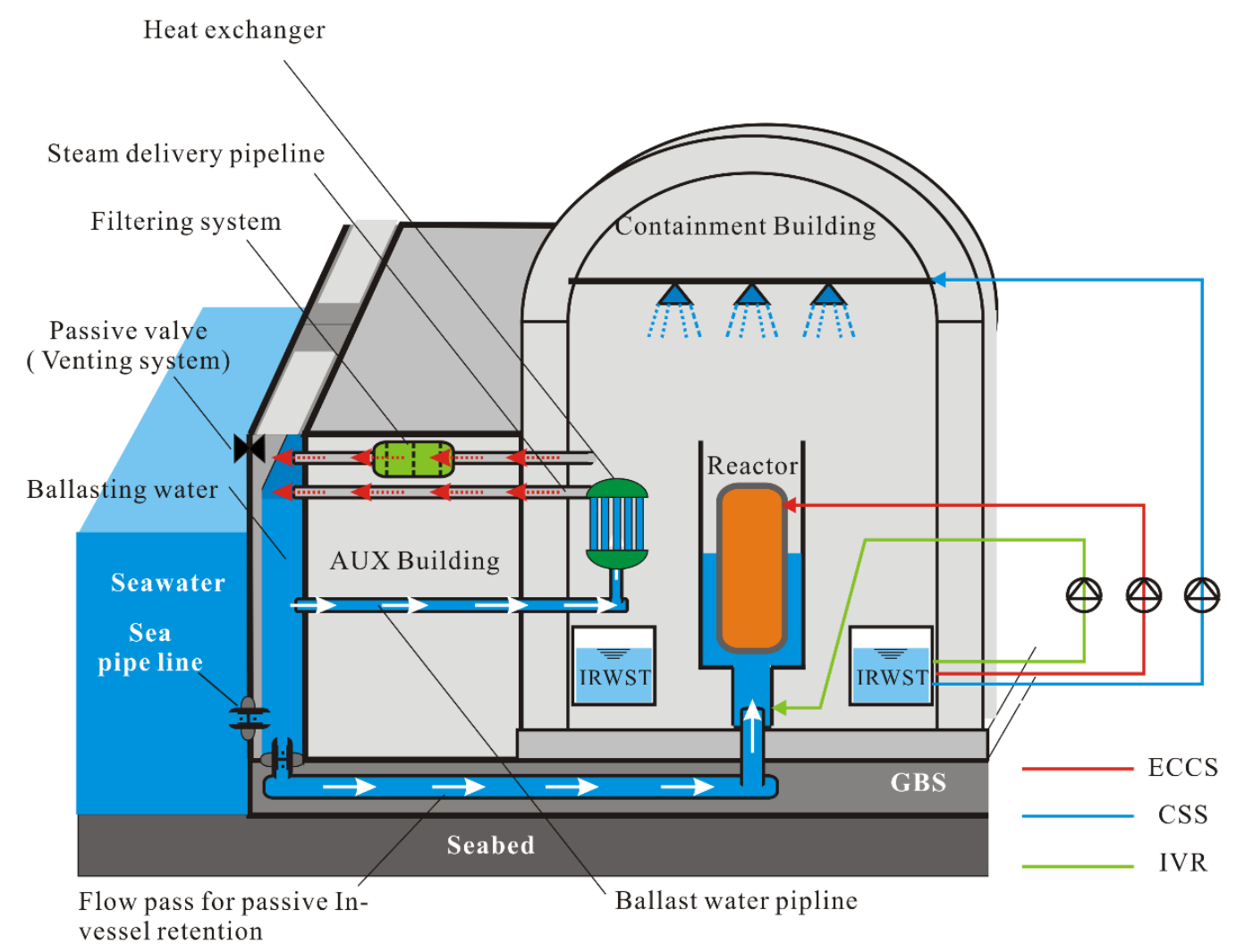

Figure 11. Emergency passive containment cooling system (EPCCS) and emergency passive reactor-vessel cooling system (EPRVCS) [19].

More recently, as shown in Figure 12, this concept has been extended to the Integrated Passive Safety System (IPSS) [31], which is an advanced integrated passive safety system being developed by a research team at KAIST in South Korea. The newly added safety system, the proposed novel construction method, and the unique locations of these types of NPPs, in conjunction, have the potential to eliminate the possibility of repeating a Fukushima-type accident. The feasibility of the GBS-type ONPP was demonstrated using the results from numerical analysis [20].

In the IPSS of a SMART ONPP, the Integrated Passive Safety Tank (IPST) replaces the existing Emergency Cooling Tank (ECT). The roles of the IPST are to provide a source of water and a heat sink. Ballast water tank and sea water serve as additional water sources. Ballast water can be injected when the water in the IPST is depleted. After depletion of the water in the ballast water tank, sea water will be injected into the IPST. There are two advantages of the IPSS on the SMART ONPP, that is, indefinite 
continuous cooling is possible and minimal design changes are needed for adaption of an IPSS to a SMART ONPP.

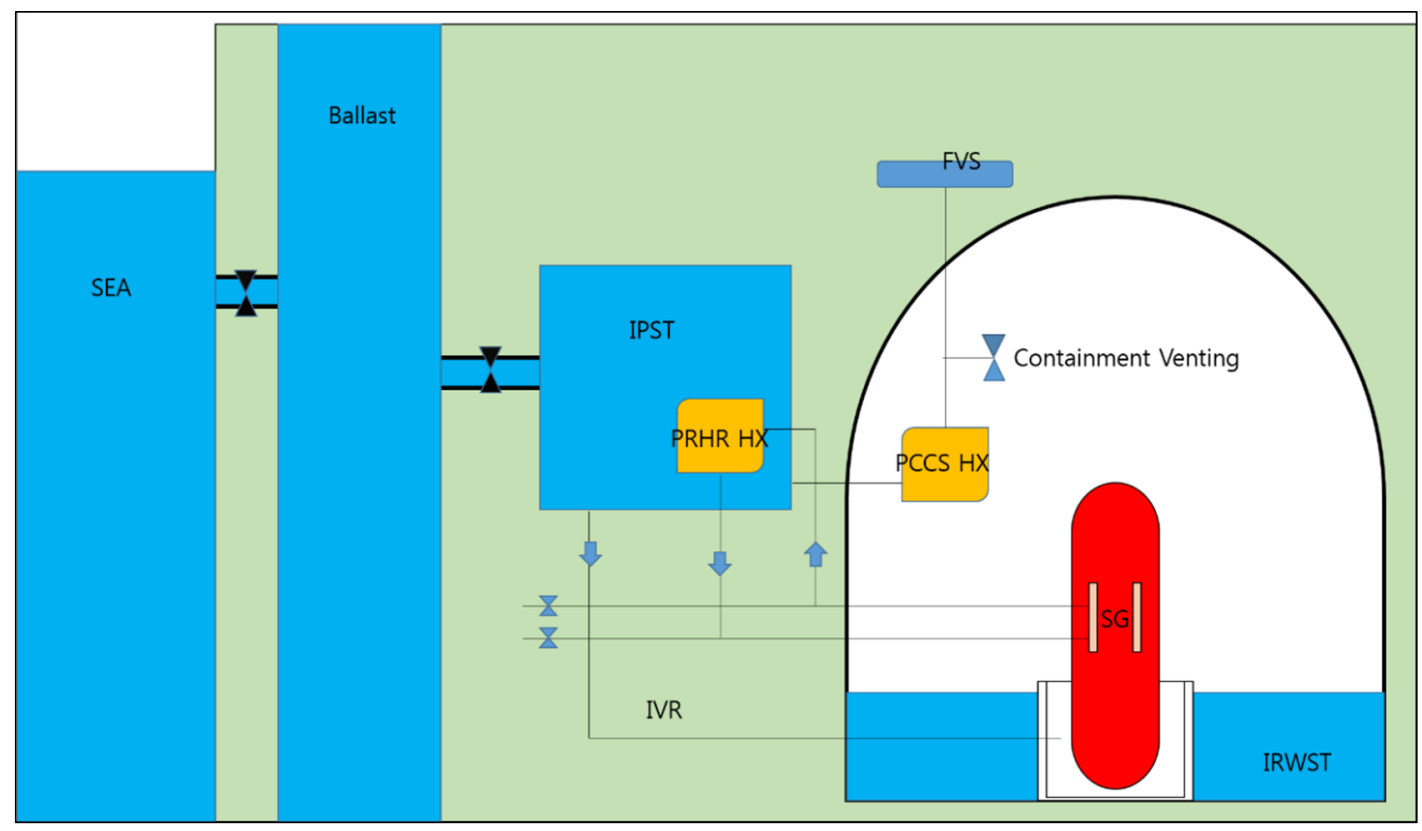

Figure 12. Integrated Passive Safety System (IPSS) on SMART ONPP [20].

\section{Submerged-Type ONPP}

DCNS in France is developing a submerged type ONPP, named Flexblue. Flexblue is a submerged, cylindrical, fully-modular, and transportable ONPP [16]. It would be installed on the seabed at a depth of $60-100 \mathrm{~m}$, at a site $5-15 \mathrm{~km}$ from the shoreline. Undersea cables would bring the electricity to customers, much like from offshore wind turbines.

This submerged reactor uses the small pressurized water reactor technology, which is similar to the French submarine reactors. In the module of Flexblue, turbine and alternator sections are separated and partitioned. Flexblue is manufactured in factories, assembled in a shipyard using naval modular construction techniques, transported by the ship, and located at the operation site. Depending on the seismic hazard, the module is either anchored horizontally on the seabed, or suspended a few meters from the bottom of the ocean with positive buoyancy. The modules can be manufactured in different places and in parallel, allowing a shorter overall construction time. The main characteristics of Flexblue are given in Table 5 and an overview is shown in Figure 13.

Table 5. Main characteristics of Flexblue, DCNS [16].

\begin{tabular}{ll}
\hline Parameter & Value \\
\hline Unit power rating & $160 \mathrm{MWe}$ \\
Length & $146 \mathrm{~m}$ \\
Diameter & $14 \mathrm{~m}$ \\
Displacement & $16,000-20,000$ ton \\
Immersion depth & Up to $100 \mathrm{~m}$ \\
Cycle length & 40 months \\
Lifetime & 60 years \\
\hline
\end{tabular}




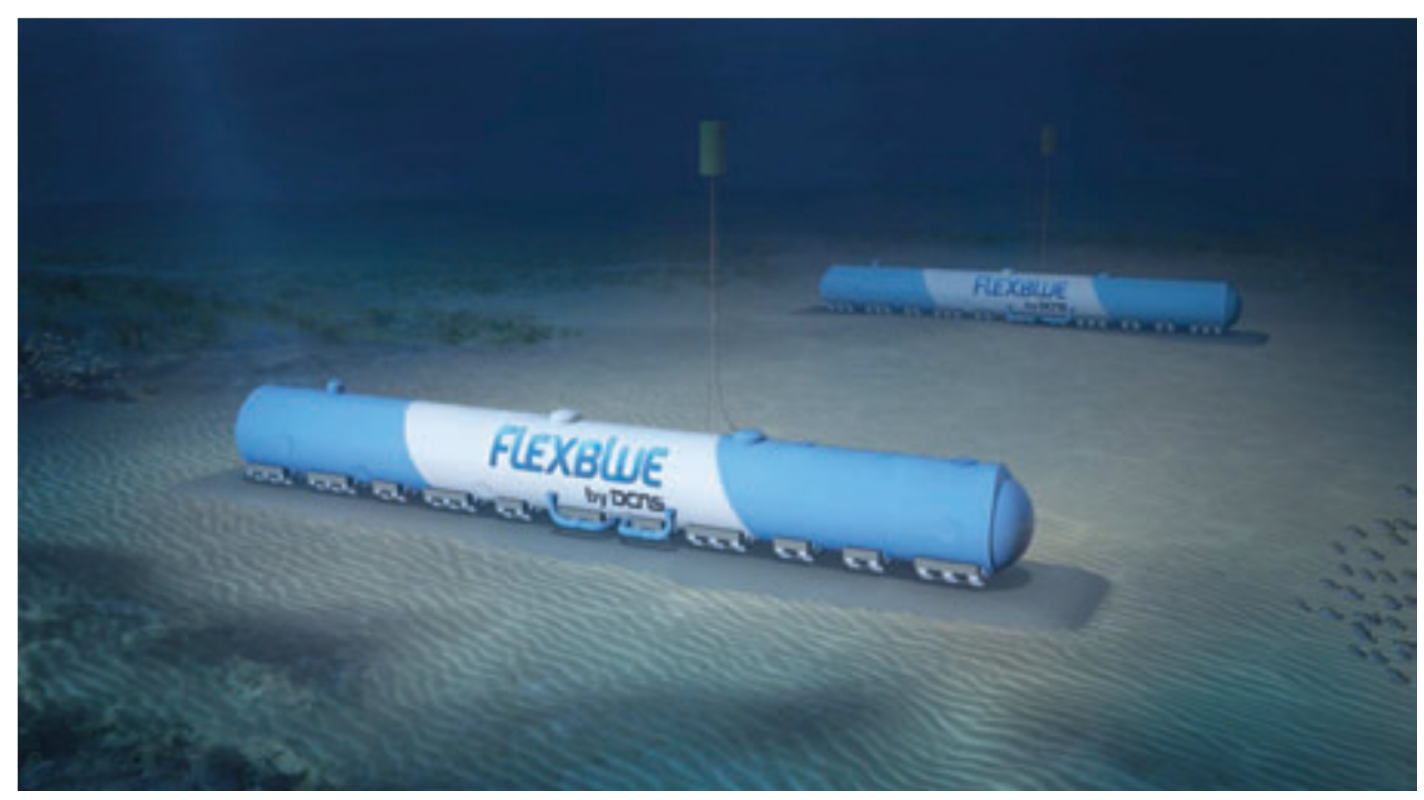

Figure 13. Flexblue deployed, DCNS [16].

Once the Flexblue is installed, it is monitored, protected, and operated from an onshore control center depicted in Figure 14. If a safety issue developed with the reactor, it could be brought to the surface and taken to a regional support facility for repair and it could be refueled the same way. At the end of its life, it could be repatriated to a shipyard for decommissioning, a process that would resemble the decommissioning of nuclear submarines.

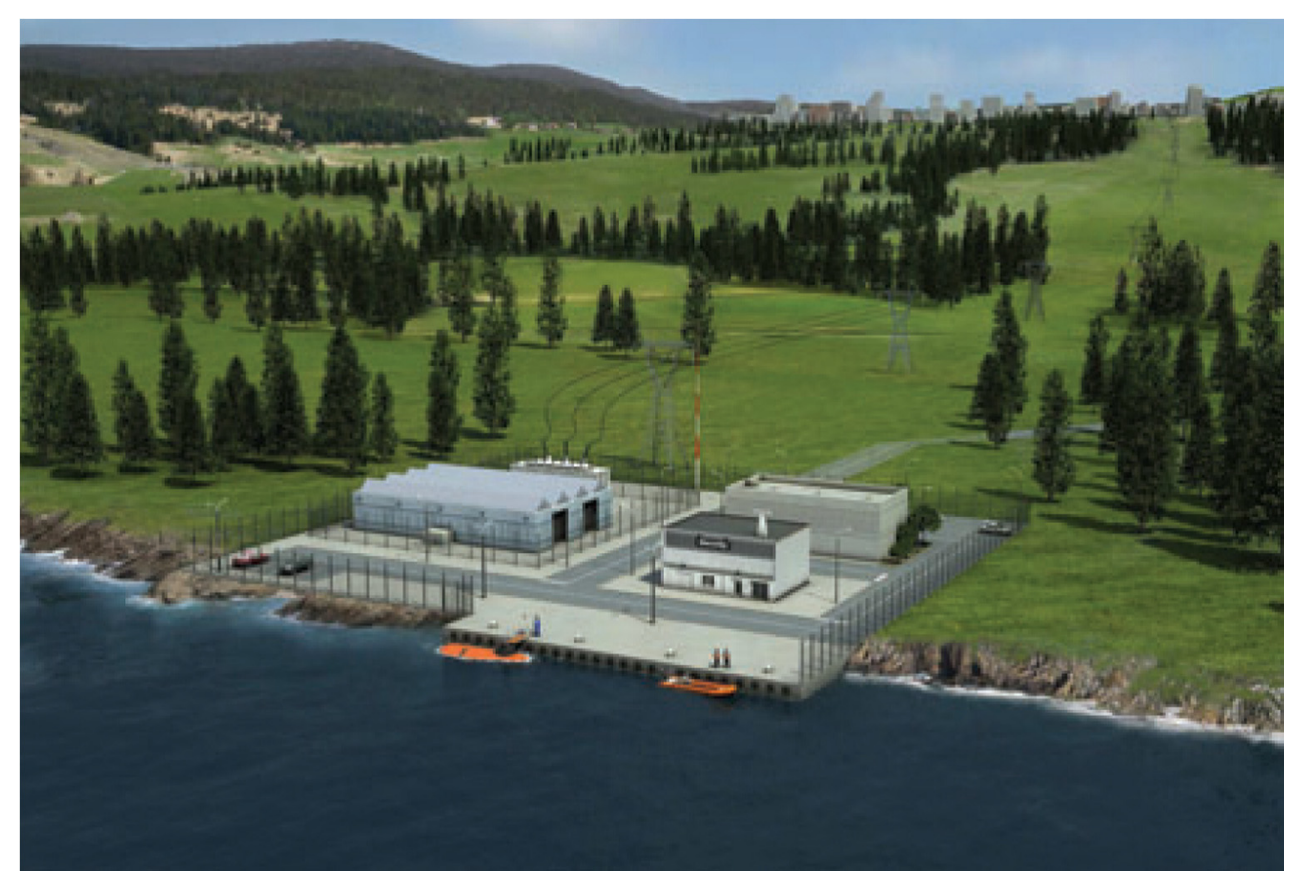

Figure 14. Onshore control center of Flexblue, DCNS [16].

The Flexblue concept adheres to European safety standards and incorporates recent developments for nuclear safety. Extreme conditions like tsunami, earthquakes, and rough weather should not impact operation of the plant. With sea water to use as a heat sink, long and efficient performance of the reactor safety systems are expected, even without external power [17]. 
In case of an accident, active systems designed for normal/shutdown core cooling, or for controlling coolant inventory, are used when AC power is available. In addition, passive safety systems are actuated automatically when emergency set points are reached. The emergency core cooling system of Flexblue can operate without external power in a both LOCA and non-LOCA situations. In a LOCA situation (Figure 15), water is injected into the primary cycle from the core makeup tank at high pressure, from the accumulator at medium pressure, and from safety tanks at low pressure by gravity. The released steam is condensed on the containment walls. Condensed water in the recirculation sump is driven to a safety tank when the gravity injection tank is empty. This system does not require pump and heat is ultimately evacuated through the containment walls to the seawater. In non-LOCA situations (Figure 16), loops on the primary and secondary circuits are used to remove decay heat. On the primary side, the heat exchangers are immerged in the safety tanks whereas on the secondary side, the heat exchangers are directly immersed in seawater and connected to the steam generators.

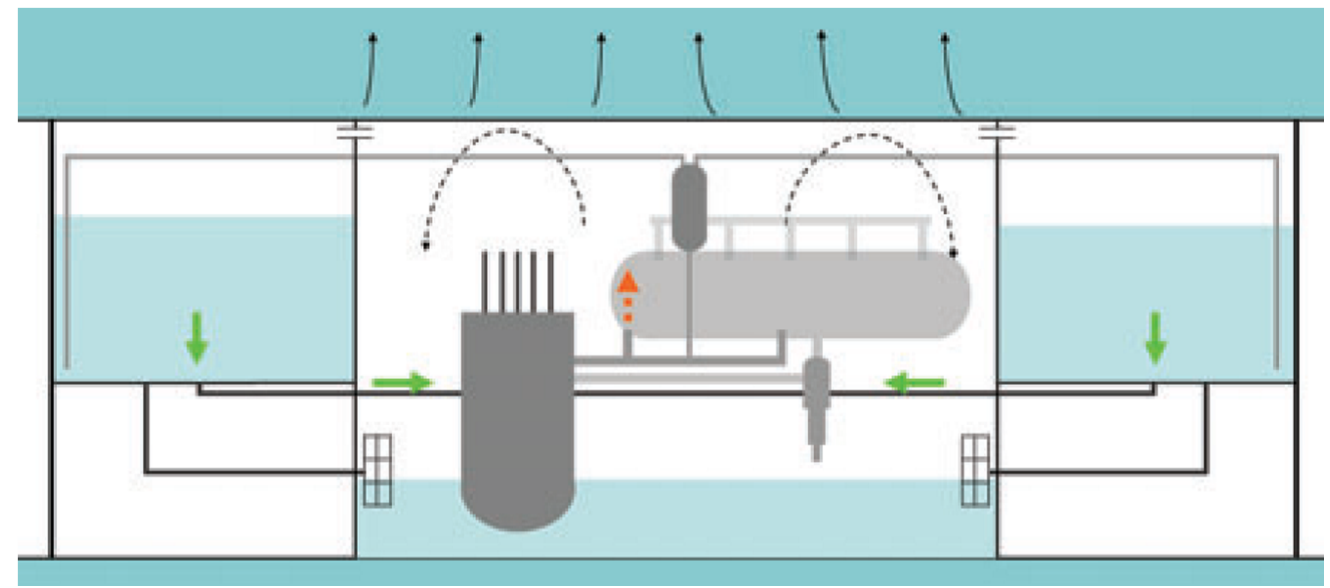

Figure 15. Passive emergency core cooling with gravity-driven injection of cold borated water from safety tanks into depressurized reactor vessel in a LOCA, DCNS [17].

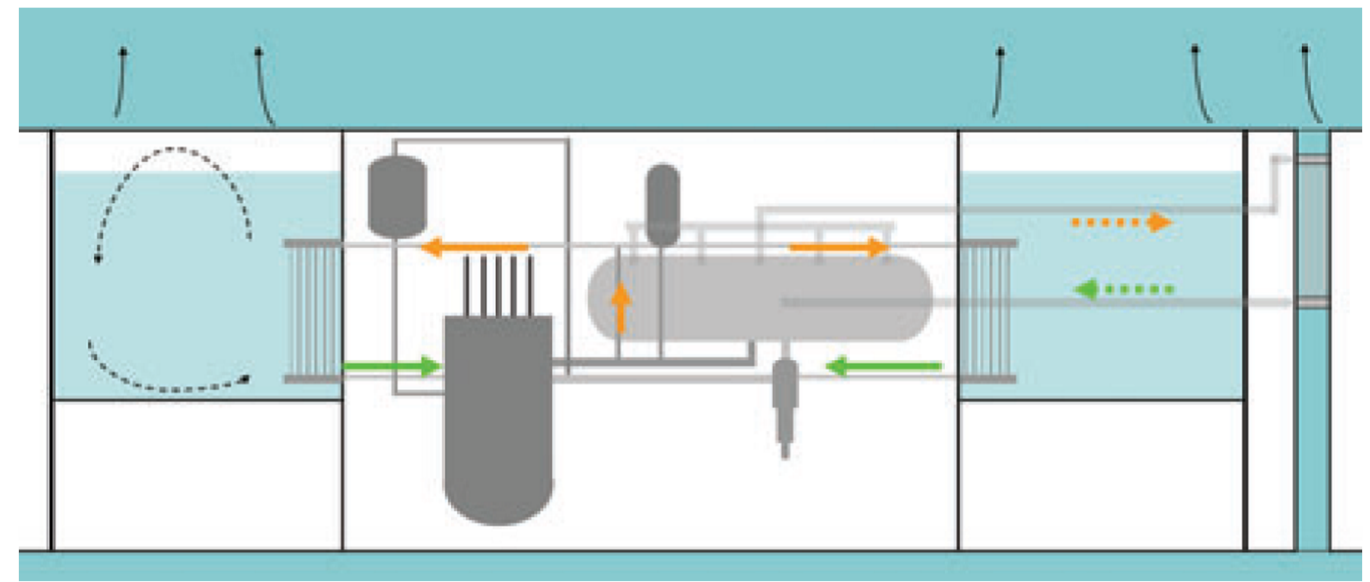

Figure 16. Passive emergency core cooling with natural circulation loops on primary and secondary circuits in a non-LOCA, DCNS [17].

Although the safety features are designed to avoid core damage, the containment is still designed to sustain a severe accident with core meltdown. Therefore, the containment of Flexblue is designed to stand severe conditions in an unexpected accident. The mitigation strategy of Flexblue includes 
in-vessel retention assisted by passive ex-vessel core cooling. If radioactive material is released into seawater in a catastrophic accident, short-term emergency counter-measures for protecting the population are not needed, unlike for a land-based reactor. Safe re-containment and retrieval of the whole nuclear station would be possible.

\section{Issues and Challenges of ONPPs}

In this section, we discuss and summarize the issues and challenges of ONPPs, as depicted in Figure 17, from the viewpoint of nuclear and ocean engineering for the sustainable developments.

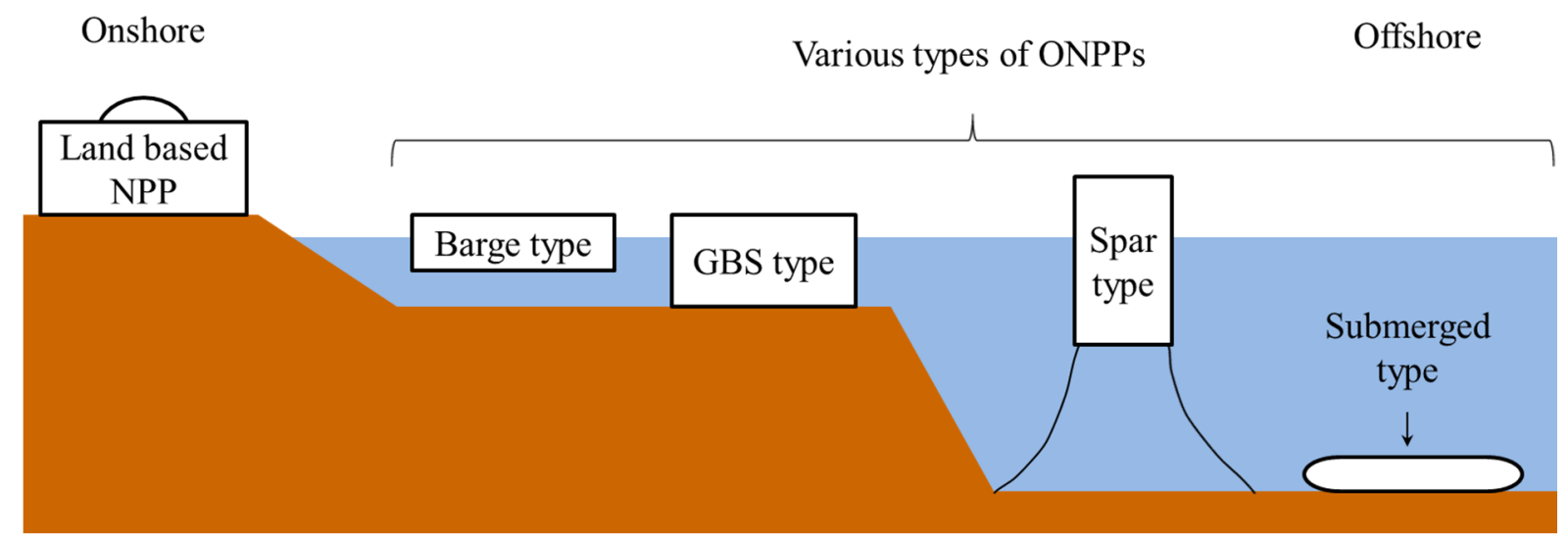

Figure 17. Various types of ONPPs.

- Construction and deployment: The ocean nuclear power plants can be built in centralized facilities like ship building yards, and is transported into installation site through ocean. This valuable feature could result in higher fabrication quality and shorter construction period. Figure 18 shows that the total construction period of ONPPs is expected to be shorter than land based NPP's because of the parallel construction procedure. That is, the fabrication of nuclear plants and the site preparation in ocean can be performed at the same time. The future expansion can be easily achieved by installing additional ONPPs adjacent to the existing facilities, without concern for acquiring additional land. Therefore, the deployment of nuclear energy systems could be accelerated.

- Tsunami: One important cause of the Fukushima nuclear accident was the power outage that was caused by the post-earthquake tsunami. Therefore, the effects of tsunami should be carefully considered in the design of ONPPs. Among the three types, the target water depth of the GBS-type ONPP is relatively shallower than the others. For this reason, Lee et al. [19] investigated the effect of Tsunami on the GBS-type ONPPs using a simple wave equation. 


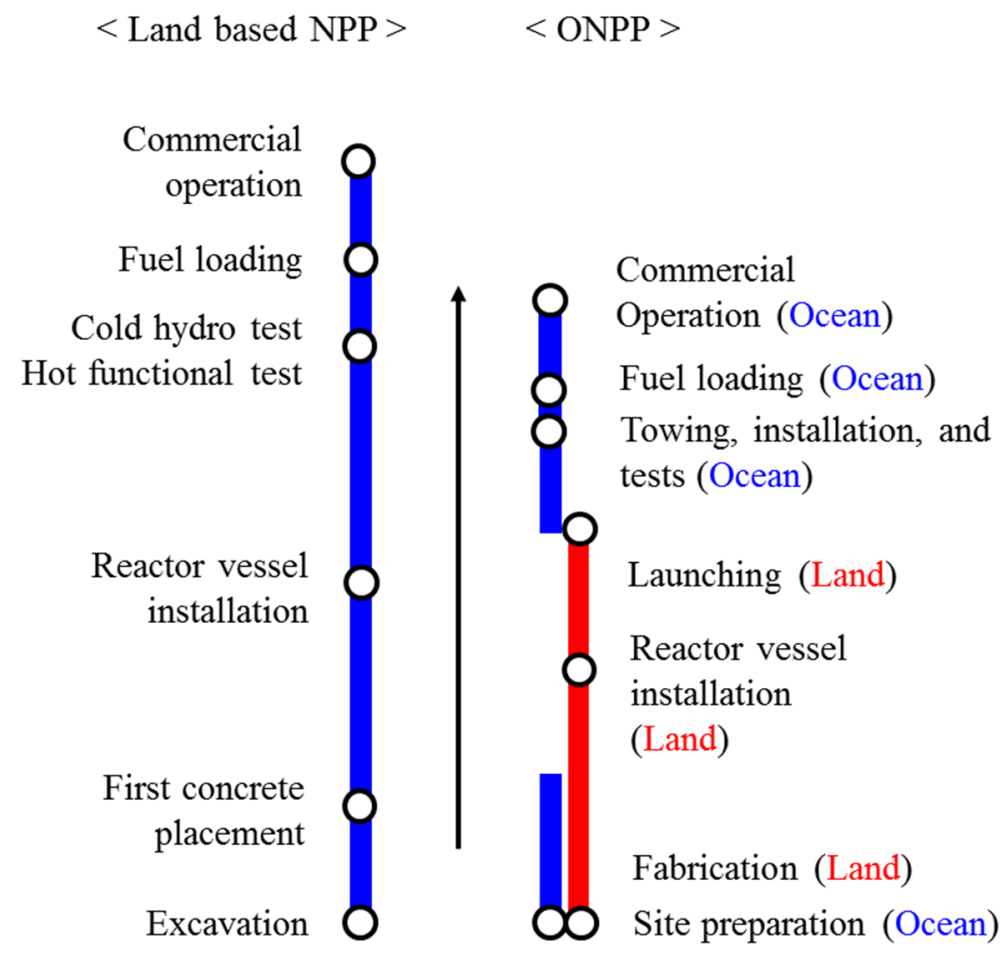

Figure 18. Construction periods of land-based NPP and ONPP.

As discussed, tsunami have a small amplitude and very long wavelength in the deep sea, but the wave height greatly increases as it moves closer to the shoreline, as shown in Figure 19. According to the conditions from the Fukushima incident, the calculated tsunami height would not exceed the freeboard of the GBS-type ONPP. This should prevent inundation of the safety systems. In contrast, the effect of tsunami is almost negligible for floating and submerged type ONPPs when the target installation location is far enough from the shoreline for safety.

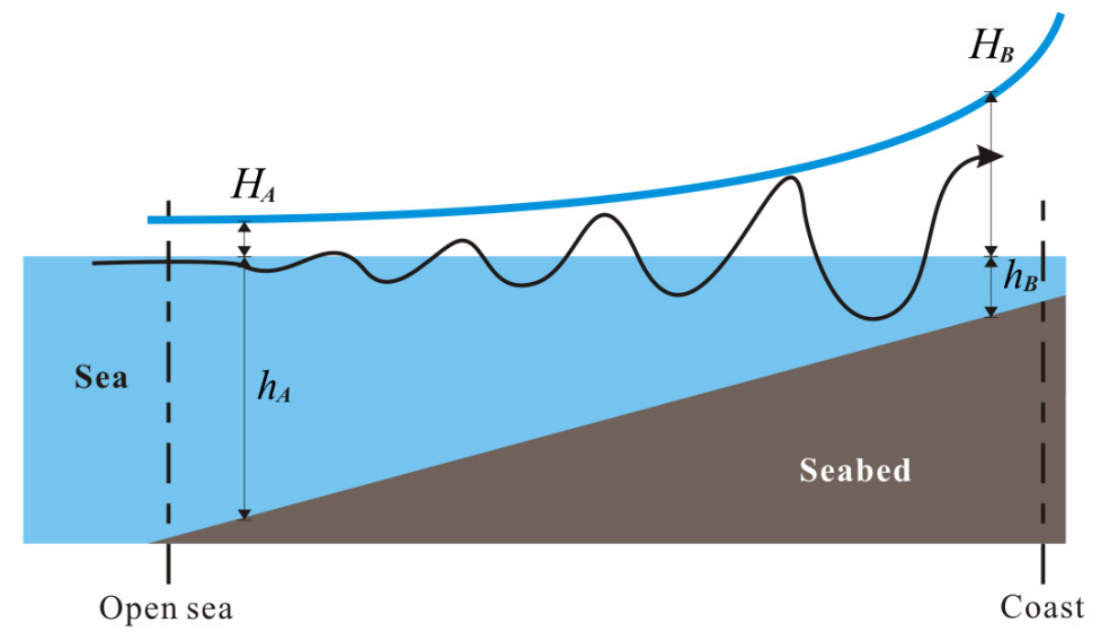

Figure 19. Wave height of a tsunami [19].

- Marine collisions: Many types of infrastructure, both near the shoreline and offshore, could be destroyed by collisions or explosions with floating objects (e.g., hijacked oil and gas carriers). With the GBS-type ONPPs, because reinforced concrete is a durable material resistant to impact loads such as marine collisions, and given that the GBS is designed to have dual concrete walls, 
the design could significantly minimize damage that might be caused by a marine collision. However, with the floating-type ONPPs, marine collisions should be carefully considered because the hull structure is usually made of steel. In addition, the mooring lines should be protected from external hazards in floating-type ONPPs, whereas submerged or GBS-type ONPPs are free from the failure of mooring lines.

- Earthquakes: During seismic loading, the GBS-type ONPPs can be damaged because the hull is settled on the sea bottom. In GBS-type ONPPs [19,20], as shown in Figure 20, a base isolation system was introduced to reduce acceleration by adjusting the total weight of the GBS [19]. This seismic isolation technology has long been applied to land-based NPPs and to other plants. Further details were described in [20]. The motions of submerged-type ONPPs should also carefully be analyzed for reaction to seismic loading because the cylindrical structure is anchored slightly above the sea bottom. Even so, earthquakes are not a principle consideration for floating-type ONPPs.

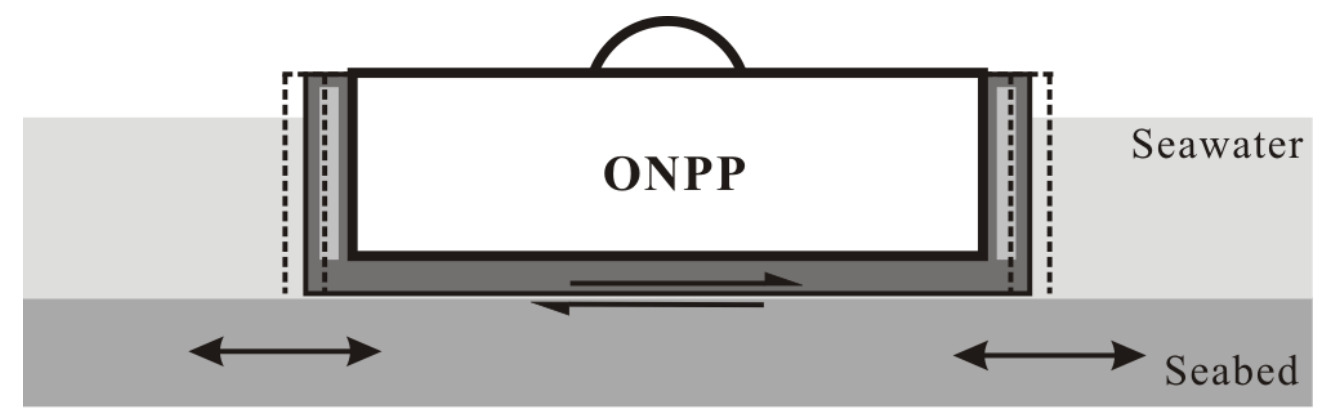

Friction base isolation system

Figure 20. Base-isolation system of GBS type ONPPs [19].

- Physical protection: Since ONPPs are located away from land, physical protection from external threats (e.g., direct attack, armed intrusion, hijacked vessels/aircraft, and sabotage) can be a challenging issue as for many offshore oil and gas platforms. Especially, underwater attack is a unique treat compared to land based NPPs, and delayed time to take security measure from land should be carefully considered. Thus, improved physical protection systems (e.g., robust hull design, additional hull protection system, and an early warning system) and measures are required to secure ONPPs compared to the land based NPPs.

- Reliability and maintenance: High plant availability plays an important role in economic competitiveness of ONPPs. High reliability can be achieved with design simplification, provision of enough operating margin, and planning extensive periodic maintenance. Since the number of operating personnel is limited in ONPPs, most of the works at ONPP site should have better plan and rely more on automated systems. Also, reducing operation and maintenance cost is an important issue for ONPPs. Table 6 shows the design recommendation for maximum acceleration of floating structures from international maritime organization (IMO). In contrast to a land-based nuclear power plant, which is designed to mainly withstand seismic acceleration (e.g., APR1400 for $0.3 \mathrm{~g}$, Westinghouse SMR for $0.25 \mathrm{~g}$ ), floating type ONPPs have to be designed to satisfy higher acceleration standard under Safety Class (SC)-1 and Plant Process Condition (PPC)-3 limit. This higher design basis acceleration will result in escalated structural integrity and acceleration isolation system for reactor safety system and emergency reactor shutdown system design. Thus, 
more improved structural design are necessary when applying current land-based nuclear reactors to ONPP. This will inevitably increase the capital cost. Therefore, in order to have advantages in economic effectiveness, decrease of operation and maintenance cost will be one of the key issues.

Table 6. Limitation of pitch, roll and yaw for nuclear merchant ships (PPC: Plant Process Class, SC: Safety Class), IMO [32].

\begin{tabular}{cccc}
\hline & Pitch & Yaw & Roll \\
\hline PPC-4 & $1.0 \mathrm{~g}$ & $1.0 \mathrm{~g}$ & $0.5 \mathrm{~g}$ \\
SC-1, PPC-3 & $0.7 \mathrm{~g}$ & $0.8 \mathrm{~g}$ & $0.4 \mathrm{~g}$ \\
SC-2,3 & $0.6 \mathrm{~g}$ & $0.7 \mathrm{~g}$ & $0.35 \mathrm{~g}$ \\
SC-4 & $0.5 \mathrm{~g}$ & $0.6 \mathrm{~g}$ & $0.3 \mathrm{~g}$ \\
PPC-1,2 & - & - & - \\
\hline
\end{tabular}

- Human errors: The ONPP should be designed to minimize potential human errors and the level of human actions needed for maintenance and operation. This is necessary to reduce the operation and maintenance cost. Since the working environment of ONPPs will be more stressful for human, and human resource will be more limited than land based NPPs, it is more likely that ONPP operators can make mistakes. Thus, the design should reduce the number of actions required by design simplification and automation. Automated equipment that could be remotely operated should be able to perform availability tests of safety-related systems.

- Others: In addition to several external hazards in ocean, there are many difficulties which should be taken into account in the design of ONPPs. Storm wind and the severe wave loads should be considered in the design of floating-type ONPPs even though they are intended to be tightly moored. The phenomenon known as a turbidity current, which results from an underwater land slide, could cause damage to underwater technology. Also, water proof compartments, corrosion, and maintenance could be the most important features affecting the life span and structural reliability of an ONPP. This is more important in design of submerged-type ONPPs because these are harder to access and repair in relatively deep water. Last, the emergency evacuation scenario and procedures should be well designed and well organized.

\section{Conclusions}

We have reviewed the recent advances in the design of ONPPs in France, Russia, South Korea, and the United States. The ONPPs were categorized as floating, GBS, and submerged types. The general arrangement, dimensions, reactor model, and safety features, including cooling systems, were discussed and summarized. Russia's ONPPs are the most developed from the viewpoint of commercialization, whereas others are still at the stage of conceptual or initial design. These share modularized design for SMRs, and for large scale ONPPs, GBS and Spar types were proposed. The ONPP design could incorporate enhanced safety features against tsunami and earthquakes, and the passive cooling systems of ONPPs are more robust than land based NPPs. The ONPP has strong potential to provide great opportunities in the nuclear power industry by decoupling the construction site from the installation site, and allows a decrease in the capital cost of total construction. Last, we commented and summarized the issues affecting ONPPs from the viewpoint of nuclear and ocean engineering. 


\section{Acknowledgments}

This work was supported by the Basic Science Research Program through the National Research Foundation of Korea (NRF), funded by the Ministry of Education, Science and Technology (No. 2014R1A1A1A05007219) and by the framework of Research and Development Program of the Korea Institute of Energy Research (KIER) (B5-2473).

\section{Author Contributions}

Kang-Heon Lee and Min-Gil Kim did the literature review and wrote the paper. Jeong Ik Lee and Phill-Seung Lee reviewed and edited the manuscript. All authors read and approved the manuscript.

\section{Conflicts of Interest}

The authors declare no conflict of interest.

\section{References}

1. Hirose, K. 2011 Fukushima Dai-ichi nuclear power plant accident: Summary of regional radioactive deposition monitoring results. J. Environ. Radioact. 2012, 111, 13-17.

2. Chu, S.; Arun, M. Opportunities and challenges for a sustainable energy future. Nature 2012, 488, 294-303.

3. Shropshire, D.; Purvins, A.; Papaioannou, I.; Maschio, I. Benefits and cost implications from integrating small flexible nuclear reactors with off-shore wind farms in a virtual power plant. Energy Policy 2012, 46, 558-573.

4. Kuznetsov, V. Options for small and medium sized reactors (SMRs) to overcome loss of economies of scale and incorporate increased proliferation resistance and energy security. Prog. Nuclear Energy 2008, 50, 242-250.

5. Rowinskia, M.K.; Whitea, T.J.; Zhao, J. Small and medium sized reactors (SMR): A review of technology. Renew. Sustain. Energy Rev. 2015, 44, 643-656.

6. Vujic, J.; Bergmann, R.M.; Skoda, R.; Miletic, M. Small modular reactors: Simpler, safer, cheaper? Energy 2012, 45, 288-295.

7. Ingersoll, D.T. Handbook of Small Modular Nuclear Reactors; Elsevier Ltd.: Cambridge, UK, 2015; pp. 27-60.

8. Hirdaris, S.E.; Cheng, Y.F.; Shallcross, P.; Bonafoux, J.; Carlson, D.; Prince, B.; Sarris, G.A. Considerations on the potential use of Nuclear Small Modular Reactor (SMR) technology for merchant marine propulsion. Ocean Eng. 2014, 79, 101-130.

9. Zav'yalov, S.N.; Sozonyuk, V.A. Marketing studies, possibilities for commercialized floating nuclear heat and power plants on the internal and external markets. Abstract of Reports at an Interdepartmental Science and Application Conference on Floating NHPP - Validation of Safety and Cost-Effectiveness, Prospects for Use in Russia and Abroad, Nizhnii Novgorod, Russia, 25-26 November 2008; pp. 3-10.

10. International Atomic Energy Agency. Status Report for Advanced Nuclear Reactor Designs; International Atomic Energy Agency: Vienna, Austria, 2011; Report 73. 
11. Lepekhin, A.; Andreeva-Andrievskaya, L.; Kuznetsov, V. Status of Russian small and medium sized reactor activities. In Proceedings of the Meeting of the International Framework for Nuclear Energy Cooperation, Rome, Italy, 6 December 2010.

12. Fadeev, Y. KLT-40S reactor plant for the floating CNPP FPU. In Proceedings of the IAEA Interregional Workshop on Advanced Nuclear Reactor Technology for Near-Term Deployment, Vienna, Austria, 4-8 July 2011.

13. Buongiorno, J.; Jurewicz, J.; Golay, M.; Todreas, N. The offshore floating nuclear plant (OFNP) concept. Nuclear Technol. 2015, in press.

14. Jurewicz, J.; Buongiorno, J.; Golay, M.; Todreas, N. Spar-type platform design for the offshore floating nuclear power plant. In Proceeding of the 10th International Topical Meeting on Nuclear Thermal Hydraulics, Operation and Safety (NUTHOS-10), Okinawa, Japan, 14-18 December 2014.

15. Kolmayer, A. Blue submarine: The Flexblue ${ }^{\circledR}$ offshore nuclear reactor. Power Eng. Int. 2011, 19, $126-131$.

16. Haratyk, G.; Lecomte, C.; Briffod, F. Flexblue ${ }^{\circledR}$ : A subsea and transportable small modular power plant. In Proceedings of the International Congress on Advances in Nuclear Power Plants 2014, Charlotte, NC, USA, 6-9 April 2014.

17. Haratyk, G.; Ingremeau, J.; Gourmel, V. CFD investigation of Flexblue ${ }^{\circledR}$ hull. In Proceedings of the Nuclear Thermal Hydraulics, Operation and Safety-10, Okinawa, Japan, 14-18 December 2014.

18. Gerwick, B.C., Jr. Construction of Marine and Offshore Structures; CRC Press: London, UK, 2007.

19. Lee, K.; Lee, K.H.; Lee, J.I.; Jeong, Y.H.; Lee, P.S. A new design for offshore nuclear power plants with enhanced safety features. Nuclear Eng. Des. 2013, 254, 129-141.

20. Kim, M.G.; Lee, K.H.; Kim, S.G.; Woo, I.G.; Han, J.H.; Lee, P.S.; Lee, J.I. Conceptual studies of construction and safety enhancement of ocean SMART mounted on GBS. Nuclear Eng. Des. 2014, $278,558-572$.

21. Bae, K.H.; Kim, H.C.; Chang, M.H.; Sim, S.K. Safety evaluation of the inherent and passive safety features of the smart design. Ann. Nuclear Energy 2001, 28, 333-349.

22. Chung, Y.J. SMART safety system. In Proceedings of the Transactions of the Korean Nuclear Society Spring Meeting, Jeju, Korea, 16-18 May 2012.

23. Kim, I.; Kim, D.S. APR1400: Evolutionary korean next generation reactor. In Proceedings of the 10th International Conference on Nuclear Engineering, American Society of Mechanical Engineers, Arlington, VA, USA, 14-18 April 2002; pp. 845-851.

24. Lapp, C.W.; Golay, M.W. Modular design and construction techniques for nuclear power plants. Nuclear Eng. Des. 1997, 172, 327-349.

25. Conant, E. Russia's new empire: Nuclear power. Sci. Am. 2013, 309, 88-93.

26. Andreeva-Andrievskaya, L.N.; Kuznetsov, V.P. Transportable nuclear power facilities in the INPRO international project. Atomic Energy 2012, 111, 340-343.

27. Khlopkin, N.S.; Pologikh, B.G.; Makarov, V.I.; Lystsov, V.N. Infrastructure of low-capacity nuclear power plants. Atomic Energy 2012, 111, 336-339.

28. Balunov, B.F.; Shcheglov, A.A.; Il'in, V.A.; Saikova, E.N.; Bol'shukhin, M.A.; Bykh, O.A.; Sokolov, A.N. An experimental substantiation of the emergency cool-down system project for the KLT-40S reactor installation of a floating nuclear cogeneration station. Therm. Eng. 2011, 58, 418-423. 
29. Kostin, V.I.; Panov, Y.K.; Polunichev, V.I.; Shamanin, I.E. Floating power-generating unit with a KLT-40S reactor system for desalinating sea water. Atomic Energy 2007, 102, 31-35.

30. Zhang, F.; Yang, J.; Li, R. A Review on the technical development of spar platform. China Offshore Platf. 2005, 2, 6-11.

31. Chang, S.H.; Kim, S.H.; Choi, J.Y. Design of integrated passive safety system (IPSS) for ultimate passive safety of nuclear power plants. Nuclear Eng. Des. 2013, 260, 104-120.

32. International Maritime Organization. Code of Safety for Nuclear Merchant Ship; International Maritime Organization: London, UK, 1981.

(C) 2015 by the authors; licensee MDPI, Basel, Switzerland. This article is an open access article distributed under the terms and conditions of the Creative Commons Attribution license (http://creativecommons.org/licenses/by/4.0/). 